\title{
ESTUDO TOPONÍMICO DOS NOMES DE BAIRROS DE SÃO LUÍS/MA
}

Heloísa Reis Curvelo-Matos

Universidade Federal do Maranhão

\section{RESUMO:}

O nome de lugar é uma testemunha do valor, da importância e das particularidades que influenciaram o denominador na hora de nomeá-lo. Fundamentada nessas premissas, esta análise consiste no estudo de atuais 81 nomes de bairros da capital do Maranhão, sob a perspectiva da sua origem e evolução histórica. Nosso intuito é determinar a motivação toponomástica de 81 nomes de lugares em quatro períodos sincrônicos, comprovando qual das duas categorias taxonômicas, a física ou a antropocultural, com suas taxes, é mais recorrente na formação do perfil toponomástico ludovicense. O corpus, fruto da pesquisa documental e de campo, é constituído de 81 topônimos oficiais usados atualmente pela Prefeitura de São Luís, e a metodologia adotada é a proposta por Dick (1990, 1994) e Curvelo (2009), que elencam 31 taxes classificatórias dos topônimos. Além desse Método Tipológico, usamos o Questionário Toponímico e Fichas Lexicográfico-Toponímicas para registrar os dados coletados em quatro áreas toponímicas: Centro, Centro-Rio Bacanga, Centro-Rio Anil e Centro-Caminho Grande. Ao final da pesquisa, constatamos que a Microtoponímia dos 81 nomes de bairros ludovicenses configura-se de 57 topônimos de natureza antropocultural, 20 de natureza física e de 04 de natureza mista, evidenciando que a motivação toponímica dos bairros foi, predominantemente, a antropocultural e não a física. Ao longo de 404 anos de história de São Luís, percebemos que a nomeação dos bairros decorre de fatores de natureza diversa: culturais, sociais, geográficos, históricos, econômicos, políticos e habitacionais. PALAVRAS-CHAVE: Lexicologia; Toponomástica; Motivação toponímica; Toponímia ludovicense. 


\section{Introdução}

A ação de nomear seres e coisas é antiga, tudo que surge vai sendo nomeado e tendo existência comprovada. A respeito desse fato, Biderman (2001) afirma que o léxico está estritamente relacionado ao processo de nomeação e à forma como concebemos ou entendemos a realidade. Em vista disso, o léxico de uma língua tem como uma de sua principal função, designar aquilo que conhecemos do universo, pois, "ao dar nomes aos seres e objetos, o homem os classifica simultaneamente. Assim, a nomeação da realidade pode ser considerada como a etapa primeira no percurso científico do espírito humano" (BIDERMAN, 2001, p. 13).

\section{Toponomástica, Toponímia, Topônimo}

A prática do saber humano de dar nomes, de fazer conhecer os nomes dados é estudada pela Onomástica ou pela Onomatologia, que é definida por Vasconcelos, em 1887, como sendo o ramo da Glotologia (palavra grega que significa estudo científico de uma língua) que se ocupa do estudo dos nomes próprios. Vale ressaltar que Vasconcelos entende por nome próprio não só o de batismo, registro ou crisma, mas o nome completo (1931, p. 04), ou seja, aquele que vem acompanhado de sobrenome e, às vezes, de apelido e alcunha. Dessa forma, o filólogo subdivide a ciência dos nomes próprios em três subáreas:

Antroponímia ou estudo dos nomes individuais, com o dos sobrenomes e apelidos; Toponímia, ou estudo dos nomes de sítios, povoações, nações, e bem como assim de rios, montes, vales, etc., - isto é, os nomes geográficos e; Vários nomes próprios, isto é que não estão contidos nas duas classes precedentes (...). (VASCONCELO, 1931, p. 03).

Para Carreter (1990), a Onomástica é um ramo da Linguística que está dividido em duas partes: Toponímia ou Toponomástica e Antroponímia. O autor esclarece que a Toponímia ou Toponomástica é parte da Onomástica destinada ao estudo dos nomes de lugar (p. 395). Outro que se ocupa do estudo dos nomes próprios é Letelier ( $\mathrm{s} / \mathrm{d}$ ). Ressalta o autor que esse estudo pode ser feito tanto do ponto de vista filológico quanto jurídico, para tanto, afirma que "se chama onomástica o sistema jurídico de denominações que seguimos em cada país para designar as pessoas, seja por estabelecimento da lei ou por costume" (p. 03). Segundo Salazar-Quijada (1985, p. 09 citado em Schneider, 2001, p. 441), “o mais antigo tesouro da lingüística e de outras realidades que não prescreveram encon- 
tra-se na toponímia. Os nomes de muitos acidentes geográficos, de todo o mundo provêm de épocas nas quais, o homem não conhecia a escritura"

Letelier destaca o caráter filológico e jurídico do estudo dos nomes, Salazar-Quijada, o etnolinguístico, e Lewandowsky (2000), por sua vez, salienta, em verbete de seu dicionário, tanto o caráter linguístico quanto o sincrônico e diacrônico, quando assim conceitua Onomástica (provém do grego a arte de dar nomes): "Estudo dos nomes. Conjunto ou sistema dos nomes ou nomes próprios como objeto de investigação linguística. Estudo dos nomes próprios" (LEWANDOWSKY, 2000, p. 245). Vale ressaltar que, para este teórico, a Onomástica, como sistema, é objeto de investigação da Linguística e que a Toponímia, como disciplina, é parte da Lexicologia.

Dick (2007b, p. 144), por sua vez, ao se referir à Onomástica, a apresenta como sendo mais do que um mero fator auxiliar das ações e da vivência individual e coletiva, "é indício de rumos tomados pelos falantes ao longo dos períodos históricos, de comportamentos presentes no cotidiano e de atitudes morais ou operosas valorizadas pela população". No que tange à Toponímia, Dick (2007b, p. 143) a situa como sendo um evento fenomenológico de múltiplas formas e sistemas. A pesquisadora acrescenta ainda que:

em sua feição intrínseca, a Toponímia deve ser considerada como fato do sistema das línguas humanas. Tanto assim que Ullmann já salientara haver o estudo dos nomes próprios se firmado recentemente, em uma quase autonomia da Lingüística, vinculado a uma ciência maior, denominada Onomástica. (DICK, 1990, p. 36).

É com esse raciocínio que Dick (2006, p. 99) explica que a Onomástica atual não afeta nem o conteúdo semântico, etimológico ou ideológico de suas ações, nem o aspecto histórico que lhe é subjacente, ou seja, a Onomástica se ocupa do estudo analítico do nome para explicar suas motivações denominativas e não para modificar sua significação.

Dick, acrescenta ainda que o onoma é definido, nas ciências onomasiológicas, não só por caracterizar a denominação de pessoas e lugares, o caráter diacrônico e sincrônico, a etimologia, as transformações morfológicas, mas porque incorpora, além de marcas fonéticas, traços causais, referenciais ou contextuais. Diante desse fato, a pesquisadora confirma que podemos conferir um duplo tratamento ao "onoma: tanto no plano interno (intracódigo ou intradisciplinar) ou no externo (intercódigo ou interdisciplinar) ". (DICK, 2002a, p. 676). 
Assim, por centrar-se também na valorização dos aspectos etnológicos, linguísticos e históricos, podemos ampliar ainda mais a definição da Toponímia seguindo os preceitos de Dick (1990, p. 19), para quem o estudo da Toponímia é importante não só por esclarecer sobre a história dos nomes de lugares presentes em qualquer espaço físico, mas por "refletir de perto a vivência do homem, enquanto entidade individual e enquanto membro do grupo que o acolhe, nada mais é que reconhecer o papel por ela desenvolvido no ordenamento dos fatos cognitivos". Isso acontece porque, no estudo da Toponímia, vamos além da simples nomeação: podemos resgatar tanto o passado, já perdido na memória, quanto o presente, atuante no registro dos Topônimos.

Percebemos, de tudo que foi dito até agora, não haver um consenso dos estudiosos a respeito da vinculação da Onomástica e da Toponímia a uma área específica. Mesmo assim, de modo geral, todos concordam que a Onomástica e a Toponímia são, respectivamente, a ciência que trata do estudo dos nomes próprios e a parte dela que trata dos nomes de lugares, ou nomes geográficos, ou ainda, mais precisamente, dos topônimos. Neste trabalho, adotaremos as posições que relacionam a Toponímia à Lexicologia, por entendermos ser o topônimo uma unidade do léxico que possui conteúdo semântico e referencial, ou seja, o topônimo não é apenas uma denominação que dada localidade tem para indicar o endereço de uma pessoa, mas o elemento local que nos permite conhecer os fatores sociais que permearam a habitação de uma dada localidade.

\section{Procedimentos metodológicos}

As técnicas que adotamos para a coleta do corpus desta pesquisa foram tanto a investigação de documentação indireta quanto a direta, já que os órgãos públicos tanto do estado quanto do município não dispõem de nenhum material bibliográfico que contenha informações sobre os históricos dos bairros, suas denominações toponímicas ou mesmo seu surgimento (datas, processos de criação, se planejados ou surgidos espontaneamente).

A pesquisa indireta foi feita em documentos oficiais do Instituto da Cidade, Pesquisa e Planejamento Urbano e Rural - INCID e também em documentos do IBGE, órgão que atualiza os dados dos indicadores sociais, servindo assim como referência aos dados usados pelo INCID para atualizar várias informações sobre a população ludovicense. A pesquisa direta foi realizada basicamente, por meio do Questionário toponímico 
que foi aplicado aos moradores das localidades que tenham vivido pelo menos uma década lá, a líderes comunitários, a artistas ou profissionais que desempenham alguma atividade social naquela área.

A lista oficial dos bairros de São Luís é composta de 210 topônimos. Nela não constam localidades de criação espontânea, bairros surgidos dentro de outros bairros, e nem os bairros novos, criados a partir da construção de condomínios de luxo, os jardins ou bairros dos conjuntos do Programa Federal Minha Casa, Minha Vida. Portanto, o corpus da pesquisa é constituído somente do recorte de 81 nomes de bairros agrupados nas 4 áreas toponímicas: Centro (11 bairros), Centro-Rio Anil (05 bairros), Centro-Rio Bacanga (05 bairros) e Centro-Caminho Grande (60 bairros).

Como etapas para a coleta de dados, seguimos: a identificação das fontes (mapas fornecidos por órgãos públicos); a transcrição e análise das informações obtidas na aplicação dos inquéritos aos informantes; a análise dos dados encontrados em material bibliográfico ou em documentos como dicionários, enciclopédias, mapas, artigos científicos, monografias, leis, decretos, resoluções, editais, certidões de registro e hipotecas de imóveis, resumos, entre outros.

No que diz respeito ao registro e arquivamento dos dados, as informações de cada bairro que compõe o corpus foram registradas em fichas lexicográfico-toponímicas elaboradas e usadas por Curvelo (2009). O referido instrumento contém os seguintes campos: topônimo e alterações toponímicas (quando há); localização do bairro; taxonomia de natureza física ou antropocultural e as notas linguísticas, históricas e enciclopédicas.

Finalmente, no que tange à análise dos dados, para descrever o léxico onomástico dos 81 topônimos, consideramos as seguintes etapas: análise dos fatores linguísticos e extralinguísticos que deixaram marcas na formação dos nomes dos bairros ludovicenses; estudo das siglas e dos termos genéricos presentes em alguns topônimos, com a finalidade de depreendermos os motivos que levaram à incorporação destes elementos aos nomes dos bairros e descobrir se houve ou não ressignificação toponímica a partir de alguns fenômenos linguísticos.

\section{Estudo toponímico dos nomes de bairros}

Sabemos que os nomes de lugares não podem ser vistos apenas como um individualizador e identificador de características de uma localidade ou como um delimitador espacial, isso acontece porque há uma 
relação estreita entre os fatores linguísticos e os socioculturais memorizados nos logradouros. Nesse sentido, os topônimos, como parte da língua de um povo, de sua documentação lexical (substratos e adstratos) de etnias e falares, espelham seus interesses, seus valores, sua realidade, estabelecendo, assim, uma relação fundamental entre a língua e a cultura dessa comunidade. Nesse caso,

os topônimos se apresentam (...) como importantes fatores de comunicação, permitindo, de modo plausível, a referência da entidade por eles designada. Verdadeiros "testemunhos históricos" de fatos e ocorrências registrados nos mais diversos momentos da vida de uma população encerram, em si, um valor que transcende ao próprio ato de nomeação: se a Toponímia situa-se como a crônica de um povo, gravando o presente para o conhecimento das gerações futuras, o topônimo é o instrumento dessa projeção temporal. (DICK, 1990 p. 21-22).

Os nomes dos topos também são importantes porque neles são registradas ocorrências históricas, sociais e linguísticas de um povo. Dick (1988, p. 84) esclarece que o topônimo é capaz de prenunciar o fenômeno social em sua totalidade, "as frases, o uso, o costume, a tradição, a conformação geral da comunidade enquanto agrupamento humano". Por isso, as várias manifestações da língua poderão manter-se vivas na Toponímia local, já que, às vezes, o topônimo é o único registro das marcas do acidente físico ou das circunstâncias que motivaram seu batismo, como podemos exemplificar com o Etnotopônimo Camboa, nome de bairro que, além de se referir a uma povoação de pescadores ou aldeia dos silvícolas que habitavam o litoral ludovicense, etimologicamente, camboa/cambôa, gamboa/ gambôa, significa cercado de tranqueiras ou fecho de paus e cipós, ou seja, armadilha para pegar peixe ou técnica muito usada pelos tupinambás para pescar.

Mesmo que seja um fato da linguagem e que tenham formam e funções semelhantes às das demais lexias de uma língua, o topônimo se distancia gradativamente do vocabulário comum, pois o que o torna especial, nesse caso, de acordo com Dick (1990b, p. 95), é “a aplicação ou o uso que se faz desse signo da língua nas disciplinas onomasiológicas, fazendo com que possa ser incluído semanticamente, em compartimentações distintas, nas taxonomias toponímicas”. Isso quer dizer que o topônimo deixa de ser apenas um qualificativo, um nominativo de um lugar para ser um documento dos fatores sociais que influenciaram no seu desenvolvimento, a exemplo como acontece com o Dirrematopônimo ${ }^{1}$ Outeiro 
da Cruz, nome de bairro composto pela variação de outeiro oiteiro que significa pequena elevação de terreno, planalto, colina, monte e cruz, símbolo máximo do Cristianismo. Nesse caso, Outeiro da Cruz vai se referir à localidade ludovicense onde os portugueses derrotaram os holandeses, em uma das batalhas sangrentas de expulsão destes, em 1642.

Outro fato interessante a pontuar é sobre o topônimo Vinhais. Quando o denominador da Vila de Eussauap, por exemplo, substituiu essa denominação por Vila dos Vinhais, uma de suas intenções era homenagear um aspecto de sua terra natal, a região dos vinhedos, mas, quando Vinhais se tornou referência para a nomeação de 11 bairros, a intenção do nomeador já não era a mesma. Inclusive as características da unidade lexical também já não eram outras, pois dizemos, por exemplo: Lá no Vinhais (singular) e não La nos vinhais (plural).

Além dessa característica interna do topônimo que o vincula a uma pesquisa linguística e etimológica, ressaltamos também suas características externas ou semânticas. No que diz respeito a essa propriedade toponímica, Dick (1990, p. 38) afirma que o nome de lugar é duplamente marcado, isto quer dizer que há a motivação lexical, a da própria palavra ou palavras e a motivação dada pelo denominar ou denominadores, dessa forma, o duplo aspecto da denominação toponímica transparecerá "primeiro na intencionalidade que anima o denominador (...) e, a seguir, na própria origem semântica da denominação". (DICK, 1990, p. 39). Em suma, mesmo que não tenha se originado como tal, temos um signo da língua que se cristalizou e se converteu em um topônimo, fenômeno observado, por exemplo no topônimo Vila Passos que, inicialmente foi Cemitério da Santa Cruz dos Passos de Nosso Senhor Jesus Cristo ou Cemitério da Irmandade do Senhor Bom Jesus dos Passos. Com o passar dos séculos, toponimicamente, só restou da referida Irmandade o qualificativo passos, antecedido do substantivo vila, isto é, bairro Vila Passos.

Para Nieto Ballester (1997, p. 11), podemos acreditar que os topônimos têm origens variadas, isto é, podem surgir de expressões linguísticas, de nomes próprios de pessoas (antropônimos) e/ou de quaisquer outras palavras que, com o passar do tempo, deixaram de ser entendidos com sua significação original. Para ilustrarmos essa afirmação de Nieto Ballester, citemos os Antropotopônimos que perpetuam nomes e sobrenomes de personalidades e profissionais, ilustres ou não, presentes na sociedade ludovicense oitocentista: o Jurista Sá Vianna (Bairro Sá Viana), o médico-cirurgião português José Maria Barreto e seu filho, o Barão 
de Anajatuba, José Maria Barreto Júnior (Bairro Barreto); a proprietária da Quinta/Sítio Lyra, Antonia Maria de Assunpção Martins Lyrio (Bairro Lira), e o dono do sítio que deu origem ao bairro homônimo, João Paulo das Chagas (Bairro João Paulo).

Podemos dizer que os topônimos surgem, também, como codificação de ideias, pensamentos, sentimentos, simbolismo religioso, que nem sempre são traduzidos na sua formulação, mas, de qualquer modo, os topônimos, por recobrirem tipicidades individuais ou regionais, caracterizam, assim, o falar local, a variedade linguística da comunidade à qual estão vinculados, daí resulta um questionamento: Fabril ou Canto da Fabril? No que tange à motivação toponímica desse Sociotopônimo, acontece um fato curioso, mesmo que o topônimo oficial seja o qualificativo Fabril, uma palavra só, quando usado popularmente, vem acompanhado de canto, fazendo menção à localização geográfica de uma fábrica que existia nesse bairro.

Outro fenômeno topônimo é o esvaziamento semântico que se refere à perda do sentido original que tinha o nome de lugar, levando-o a ficar completa ou parcialmente opaco, a exemplo do que acontece com o topônimo ludovicense Apicum: apicum $=$ terreno alagadiço $>$ Apicum $=$ bairro). Isso se dá "seja porque sufixos latinos que lhes foram agregados não mais se usam em português, seja porque sua acomodação na toponímia criou uma similaridade a outros sufixos, conduzindo a falsas interpretações" (CARVALHINHOS et. al., 2007, s/p).

Esses outros sufixos (e ou prefixos) que a pesquisadora cita, poderiam ser os de origem indígena, que, por desconhecimento, acabam não sendo ou sendo mal-interpretados etimologicamente, quando buscamos analisar a motivação toponímica original que se perdeu ao longo dos anos, como aconteceu com o Etnotopônimo Bacanga/Ibacanga: iba é braço e canga, cabeça, logo o Rio Bacanga (afluente que desaguam na Baia de São Marco). Tibiriçá (1985, p. 27) registra ybá-canga que, dependendo do contexto onde figure, pode significar rio do Maranhão e também fruto seco, baga, coquinho.

Reiteramos do que foi dito, que subjacente à ação de nomear, há intenções bem delineadas, mas que se tornam menos claras considerando o seu esvaziamento semântico pelo decurso do tempo entre a criação do termo e o seu emprego". (DICK, 2006, p. 99). Exemplificamos esse fenômeno quando nos reportamos a tantas alterações toponímicas que o lugar passa ao longo de sua história. Vinhais Velho, por exemplo, sofreu 
7 alterações toponímicas desde que foi criado (Aldeia de Eussauap $>$ Vila Uçaguaba $>$ Aldeia da Doutrina $>$ Aldeia de São João dos Poções $>$ Vila dos Vinhais $>$ Freguesia do Vinhais $>$ Freguesia de São João Batista dos Vinhais $>$ Vinhais Velho), mas mesmo que cada denominação tivesse uma motivação específica, o elemento que permaneceu até a atualidade, não resgata a Aldeia de Eussauap ou os índios que foram aculturados, mas o povo que os dominou, daí a permanência do topônimo Vinhais, que homenageia uma região dos vinhedos de Portugal.

Mesmo havendo o esvaziamento semântico do topônimo, pode acontecer o contrário também, pois o topônimo pode adquirir novos sentidos, ressemantizando-se. O fenômeno da ressemantização toponímica nada mais é do que o topônimo assumir "um segundo significado, para um mesmo significante", segundo Carvalhinhos (2007, p. 28). Quando observarmos, por exemplo, que $\mathrm{COHAB}$, originalmente, significava Companhia de Habitação Popular e que Cohab, popularmente, é uma grande área formada de 4 bairros (Conjunto Habitacional Anil I, II, III, IV), conseguimos entender esse processo de ressemantização do topônimo.

Destacamos também os arquétipos toponímicos que são formados por substantivos comuns que funcionam como estruturas motivadas, ou seja, são formas descritivas que carregam em si a significância do topônimo que nomeiam. Para Dick (1987, p. 99), os arquétipos toponímicos são "expressões padrões que traduzem ou enfocam o mesmo ângulo em relação à caracterização do acidente geográfico. Assim, os diversos sistemas toponímicos apresentam expressões que significam o mesmo fato, ou traduzem uma condição semelhante".

A partir dos arquétipos toponímicos, podemos perceber que os elementos constitutivos do signo toponímico podem evidenciar um vínculo estreito entre ele e seu referente, traduzindo assim a espontaneidade do denominador no ato da nomeação. Nesse caso, o topônimo ludovicense, o nome de bairro, pode transparecer: cor (Aurora), forma (Forquilha, Ilhinha), tamanho (Outeiro da Cruz), constituição natural (Ponta d'Areia), elemento constitutivo (Areinha). Em síntese, pode demonstrar uma referência direta a aspectos físicos e antropoculturais, projetando características reais e visíveis como acontece com o topônimo Forquilha.

Além dos arquétipos toponímicos provenientes de substantivos, temos também os que se originam dos adjetivos como: atlântico, novo e velho, como é o caso de: (Jardim) Atlântico, (Maranhão) Novo e (Vinhais) Velho, que deixam transparecer a objetividade do denominador no ato da 
nomeação, passando assim, da denotação para a conotação. Isso acontece, segundo Dick (1995, p. 61), porque a "emotividade do sujeito, torna-se mais perceptível à medida que o sistema de comunicação toponímica joga com termos adjetivos, seja para precisar contornos diferenciadores ou para revelar um estado de ânimo".

Como já dissemos, o topônimo não é um signo linguístico especial, mas um nome comum que adquiriu várias funções, entre elas, nomear lugares. Por isso, em sua formação gramatical, agregam elementos "fonéticos, morfológicos, sintáticos e semânticos próprios da língua, elementos fósseis e inativos, como que pertencentes a uma língua morta, conservando seu valor expressivo, incorporado à nossa fala" (MENENDEZ PIDAL 1952, p. 05). Para ilustrar essa afirmação, citemos o afixo -rama (região das palmeiras), que aparece na formação sufixal de topônimos como Pindorama, e o sufixo - rana (semelhante a, parecido a, da feição de), que aparece na formação sufixal dos topônimos/bairros Conjunto Residencial Jeniparana e Vila Jeniparana.

Ainda sobre os elementos constituintes do topônimo, não podemos esquecer que um nome, funcionando como topônimo, pertence à classe gramatical dos substantivos e pode apresentar uma estrutura simples (Jordoa), composta (Cruzeiro de Santa Bárbara), ou mesmo aparecer como combinação de vários elementos linguísticos que podem ser, desde um simples substantivo ou até formas mais complexas, como: Cohab Anil I, que significa Companhia de Habitação Popular do Maranhão do Rio Anil, etapa I, para diferenciar dos demais conjuntos construídos pela inativa Companhia, Cohab Anil, etapas II, III e IV.

Dick (2007a, p. 146) afirma que, em sua constituição como léxico da língua, o topônimo pode compreender lexias: (i) simples, formadas por substantivo + adjetivo: Cidade Operária; substantivo + verbo: Conjunto Habitar; (ii) compostas por substantivo-adjetivo: Primavera-Coroado e (iii) complexas ou estáveis: Cohab Anil I (Companhia de Habitação Popular do Maranhão que não é usado em detrimento de Cohab que se estabilizou no léxico toponímico).

Para Câmara Júnior (1986, p. 232-233), os topônimos brasileiros, ainda sem grandes mudanças fonéticas, representam: (i) nomes comuns, ou locuções substantivas, de caráter descritivo: Goiabal; (ii) nomes de santos padroeiros: São Cristóvão; (iii) reprodução de topônimos portugueses ou de imigrantes ou topônimos transplantados: Sacavém; (iv) tupinismos e africanismos, com intenção descritiva: Itapiracó e Rua do Mo- 
cambo $^{2}$; (v) nomes de autoridades governamentais ou homens públicos: Vila Airton Senna.

Quando analisamos os topônimos levando em consideração o ponto de vista interno de sua estrutura, da constituição dos elementos que o formam e da sua motivação, projetamo-los em uma terminologia taxonômica ou em taxes léxico-semânticas. A terminologia taxonômica que é utilizada no Brasil foi proposta por Dick, que delineou 27 taxes léxico-semânticas, das quais, 11 são físico-naturais e 16 antropoculturais. "Mas a palavra ou a unidade lexical, recortada em um desses dois universos de ocorrências, examinada do ponto de vista linguístico ou das famílias envolvidas, é que norteou a sua inclusão seja no campo físico ou no antropocultural" (DICK, 1990, p. 37-40). Essas taxes explicativas têm por finalidade a transmissão das causas que justificam a denominação dos nomes de lugares sem que precisemos recorrer ao denominador propriamente dito.

A partir desse esclarecimento, a pesquisadora faz um alerta de fundamental importância, no que diz respeito às dificuldades de recuperação dos motivos primários dos topônimos, de seus condicionantes, de sua classificação em um ou outro campo, em uma ou noutra classe. Nesse caso, Dick (2006, p. 107) afirma que "nem sempre as lexias têm um sentido único que permita a sua correta inclusão em um campo semântico incontroverso", dessa forma temos o aspecto físico e o antropocultural. O primeiro trata dos elementos da paisagem, do ambiente ou do espaço físico (quadro 1). No que compete ao aspecto antropocultural, os elementos podem se referir às atividades humanas, de forma geral (quadro 2).

Quadro 01: Taxes de natureza física

\begin{tabular}{|l|l|}
\hline CLASSIFICAÇÃO & TOPÔNIMOS REFERENTES \\
\hline Astrotopônimos & aos nomes dos corpos celestes: Rua do Sol. \\
\hline Cardinotopônimos & às posições geográficas em geral: Centro. \\
\hline Cromotopônimos & à escala cromática: Aurora \\
\hline Dimensiotopônimos & às características dimensionais: Caminho Grande. \\
\hline Fitotopônimos & aos nomes de vegetais: Goiabal. \\
\hline Geomorfotopônimos & às formas topográficas: Ilhinha. \\
\hline Hidrotopônimos & acidentes hidrográficos: Rio Anil. \\
\hline Litotopônimos & aos nomes de minerais: Diamante. \\
\hline
\end{tabular}




\begin{tabular}{|l|l|}
\hline Meteorotopônimos & aos fenômenos atmosféricos: Primavera (Cohajap). \\
\hline Morfotopônimos & às formas geométricas em geral: Forquilha. \\
\hline Zootopônimos & aos nomes de animais em geral: (Vila) Cascavel. \\
\hline
\end{tabular}

Quadro 02: Taxes de natureza antropocultural

\begin{tabular}{|l|l|}
\hline CLASSIFICAÇÃO & TOPÔNIMOS REFERENTES \\
\hline Animotopônimos & à vida psíquica, cultura e espiritual: Liberdade. \\
\hline Antropotopônimos & aos nomes próprios e individuais: Ivar Saldanha. \\
\hline Axiotopônimos & aos títulos e dignidades: Vila Dom Luís. \\
\hline Corotopônimos & $\begin{array}{l}\text { aos nomes de cidades, países, regiões ou continentes: } \\
\text { Sacavém. }\end{array}$ \\
\hline Cronotopônimos & às indicações cronológicas: Novo Angelim. \\
\hline Ecotopônimos & a habitações em geral: Chácara (Brasil). \\
\hline Ergotopônimos & $\begin{array}{l}\text { a elementos da cultura: Salina (do Sacavém, da Vila } \\
\text { Palmeira). }\end{array}$ \\
\hline Etnotopônimos & aos elementos étnicos isolados ou não: Camboa. \\
\hline Dirrematopônimos & a frases ou expressões linguísticas: Outeiro da Cruz \\
\hline Hagiotopônimos & $\begin{array}{l}\text { aos nomes sagrados do hagiológio romano: São Fran- } \\
\text { cisco. }\end{array}$ \\
\hline Hierotopônimos & aos nomes sagrados de diferentes crenças: Santa Cruz. \\
\hline Historiotopônimos & $\begin{array}{l}\text { aos movimentos histórico-sociais, às suas datas: Ape- } \\
\text { adouro. }\end{array}$ \\
\hline Hodotopônimos & $\begin{array}{l}\text { às vias de comunicação rural ou urbana: Caminho da } \\
\text { Boiada }\end{array}$ \\
\hline Mitotopônimos & às entidades mitológicas: Conjunto Centaurus. \\
\hline Numerotopônimos & aos adjetivos numerais: Cohatrac IV. \\
\hline Poliotopônimos & $\begin{array}{l}\text { aos vocábulos aldeia, vila, povoação e arraial: Vila } \\
\text { Janaína. }\end{array}$ \\
\hline às siglas: Coheb - Companhia Hidrelétrica de Boa \\
Esperança.
\end{tabular}


Curvelo (2009, p. 94) propõe que os Dirrematopônimos sejam agrupados tanto na categoria de topônimos antropoculturais quanto físicos já que, dependendo do Dirrematopônimo, podemos ter um aspecto antropocultural e também um físico, espelhados num mesmo topônimo: Outeiro $=$ planalto (aspecto físico) + da Cruz (aspecto antropocultural). Logo, à classificação de Dick, é acrescido o Dirrematopônimo misto e também outra taxe proposta por Curvelo, o Siglatopônimo.

Observamos que há uma incidência significativa de topônimos formados por siglas que se esvaziaram semanticamente, isto é, não são mais reconhecidas nem na ortografia e nem usualmente como tal. Dessa forma, os Siglatopônimos são topônimos que se originaram de siglas de nomes de instituições, empresas, casas comerciais, indústrias, marcas de fábrica, de propaganda e afins. Nesse caso, a sigla que deu origem ao nome de lugar, não é mais reconhecida como sigla, mas como uma nova palavra, estabilizada na língua, assim, o Siglatopônimo pode ser obtido por:

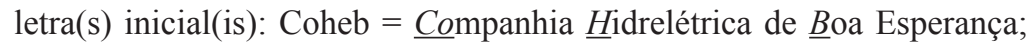

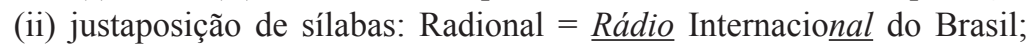
(iii) justaposições arbitrárias de componentes dos nomes, expressões ou frases já usadas gráfica ou circunstancialmente: Cohatrac $=\underline{\text { Cooperativa }}$

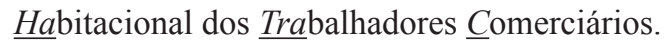

\section{Considerações finais}

Sinteticamente, dentre os 81 topônimos pesquisados, analisamos a motivação toponímica somente de 01 cardinotopônimo, 35 dirrematopônimos, 01 fitotopônimo, 01 geomorfotopônimo, 01 hidrotopônimo, 02 litotopônimos, 01 zootopônimo, 02 animotopônimos, 07 antropotopônimos, 03 corotopônimos, 02 cronotopônimos, 07 etnotopônimos, 08 hagiotopônimos, 02 hierotopônimos, 02 historiotopônimos, 01 hodotopônimo, 01 mitotopônimo, 03 siglotopônimos e 01 sociotopônimo.

Dentre os 81 topônimos pesquisados, 55 passaram por alterações toponímicas, resultantes de variadas motivações e 26 não passaram por esse processo. Destarte, ao longo dos 404 anos de São Luís sofreram alterações toponímicas: Alemanha, Anil, Anjo da Guarda, Apeadouro, Apicum, Areinha, Bairro de Fátima, Camboa, Caratatiua, Centro, Chácara Brasil, Cidade Operária, Coheb, Conj. Habitacional Bequimão, Conjunto Habitacional Angelim, Conjunto Habitacional Anil I, Conjunto Habitacional Anil II, Conjunto Habitacional Anil III, Conjunto Habitacional Anil IV, Conjunto Habitacional Rio Anil, Coréia, Cutim Anil, Desterro, 
Diamante, Fé em Deus, Filipinho, Forquilha, Goiabal, Itapiracó, Ivar Saldanha, Jardim América Central, Jardim Atlântico, João Paulo, Liberdade, Madre Deus, Monte Castelo, Olho d'água, Outeiro da Cruz, Ponta d'areia, Radional, Sá Viana, Sacavém, Salina do Sacavém, Santa Efigênia, Santo Antonio, São Bernardo, São Francisco, São Marcos, Túnel do Sacavém, Turu, Vila Bacanga, Vila Janaína, Vila Palmeira, Vila Passos e Vinhais Velho.

Por outro lado, não sofrem quaisquer alterações os seguintes topônimos Barreto, Bom Jesus, Bom Milagre, Cidade Olímpica, Cohafuma, Conjunto Habitacional Turu, Conjunto Habitacional Vinhais, Coroadinho, Fabril, Ilhinha, Jardim América, Jordoa, Lira, Maiobinha, Mauro Fecury I, Mauro Fecury II, Novo Angelim, Parque Amazonas, Planalto Aurora, Ponta do Farol, Retiro Natal, Santa Cruz, Santa Rosa, Vila Airton Senna, Vila Cascavel e Vila Isabel Cafeteira.

Quadro 3: Classificação dos topônimos de natureza física

\begin{tabular}{|l|l|}
\hline CLASSIFICAÇÃO & DEFINIÇÕES \\
\hline Cardinotopônimos & Centro \\
\hline Dirrematopônimos & $\begin{array}{l}\text { Conjunto Habitacional Angelim, Conjunto Habitacio- } \\
\text { nal Anil I, Conjunto Habitacional Anil II, Conjunto } \\
\text { Habitacional Anil III, Conjunto Habitacional Anil IV, } \\
\text { Conjunto Habitacional Rio Anil, Conjunto Habitacio- } \\
\text { nal Turu, Conjunto Habitacional Vinhais, Parque Ama- } \\
\text { zonas, Ponta d'areia, Ponta do Farol, Vila Bacanga, } \\
\text { Vila Palmeira. }\end{array}$ \\
\hline Fitotopônimos & Goiabal \\
\hline Geomorfotopônimos & Ilhinha \\
\hline Hidrotopônimos & Anil \\
\hline Litotopônimos & Diamante, Areinha \\
\hline Zootopônimos & Vila Cascavel \\
\hline
\end{tabular}


Quadro 4: Taxes de natureza antropocultural

\begin{tabular}{|l|l|}
\hline CLASSIFICAÇÃO & DEFINIÇÕES \\
\hline Animotopônimos & Liberdade, Coroadinho \\
\hline Antropotopônimos & $\begin{array}{l}\text { Barreto, Filipinho, Ivar Saldanha, João Paulo, Jordoa, } \\
\text { Lira, Sá Viana. }\end{array}$ \\
\hline Corotopônimos & Alemanha, Coréia, Sacavém. \\
\hline Cronotopônimos & Novo Angelim, Vinhais Velho. \\
\hline Etnotopônimos & $\begin{array}{l}\text { Cutim Anil, Turu, Camboa, Maiobinha, Apicum, Cara- } \\
\text { tatiua, Itapiracó. }\end{array}$ \\
\hline Dirrematopônimos & $\begin{array}{l}\text { Bairro de Fátima, Bom Jesus, Bom Milagre, Chácara } \\
\text { Brasil, Cidade Olímpica, Cidade Operária, Conjunto } \\
\text { Habitacional Bequimão, Fé em Deus, Jardim Améri- } \\
\text { ca Central, Jardim América, Jardim Atlântico, Mauro } \\
\text { Fecury I, Mauro Fecury II, Retiro Natal, Vila Airton } \\
\text { Senna, Vila Isabel Cafeteira, Vila Janaína, Vila Passos. }\end{array}$ \\
\hline Hagiotopônimos & $\begin{array}{l}\text { Desterro, Madre Deus, São Bernardo, São Francisco, } \\
\text { São Marcos, Santa Efigênia, Santa Rosa, Santo Anto- } \\
\text { nio. }\end{array}$ \\
\hline Hierotopônimos & Santa Cruz, Anjo da Guarda. \\
\hline Historiotopônimo & Monte Castelo, Apeadouro. \\
\hline Hodotopônimos & Forquilha \\
\hline Mitotopônimos & Olho d'água \\
\hline Siglotopônimos & Coheb, Cohafuma, Radional. \\
\hline Sociotopônimos & Fabril. \\
\hline
\end{tabular}

As causas histórico-evolutivas que motivaram a nomeação dos 81 topônimos evidenciam que eles são autênticos testemunhos históricos de fatos e ocorrências registrados nos mais diversos momentos da História de São Luís, por isso, encerram em si a importância que transcende ao próprio ato de nomeação dos logradouros. "Se a Toponímia situa-se como a crônica de um povo, gravando o presente para o conhecimento das gerações futuras, o topônimo é (...) a projeção temporal”. (DICK, 1990 p. 21 22). É a partir do topônimo que uma dada realidade social pode ser desvelada, conhecida, desvencilhada através dos tempos, neste caso, 404 anos. 


\section{A TOPONYMIC STUDY ON DISTRICTS NAMES OF SÃO LUÍS/MA}

\section{ABSTRACT}

A place name testifies the value, the importance and the particularities which have influenced the denominator when it comes to naming it. Based on these arguments, this analysis consists of the study of the current 81 Maranhão's capital districts names through the origin and historical development perspective. Our aim is to determine the toponymic motivation of 81 place names proving which of these two taxonomic categories, physics or antropocultural, with their taxes, is more recurrent in the toponymic creation in São Luís city, divided into four synchronic periods. As a result of the documental and field research, the corpus consists of 81 official place names currently used by the city hall of São Luís and the chosen methodology is based on the approach of Dick (1990, 1994) and Curvelo (2009) which recommends 31 toponymic classifications. In addition to this Typological Method, the Toponymic questionnaire and the lexical-toponymic forms were used to register the collected data of the four toponymic areas: Center, Center-Rio Bacanga, Center-Rio Anil and CenterCaminho Grande. At the end of the research, we observed that the Microtoponymy of 81 district names of São Luis is composed of 57 toponyms of antropocultural nature, 20 of physical nature and 04 of mixed nature, demonstrating that the motivation of the locative was primarily antropocultural and not physical. Over the course of 404 years of São Luis history, the districts nominations is due to many factors: cultural, social, geographic, historical, economic, political and housing.

KEYWORDS: Lexicology; Toponomastic; Toponymic motivation; São Luís toponymy 


\section{NOTAS}

${ }^{1}$ Topônimos originados de expressões linguísticas.

${ }^{2}$ Acrescentamos aqui o nome de uma rua e não de um bairro, porque, até o presente, não encontramos topônimos de origem africana na nomeação de municípios maranhenses ou bairros ludovicenses.

\section{REFERÊNCIAS}

BIDERMAN, Maria Tereza Camargo. Fundamentos da Lexicologia. In: Teoria Linguística: teoria lexical e linguística computacional. São Paulo: Martins Fontes, 2001.

CARRETER, Fernando Lázaro. Diccionario de términos filológicos. 3. ed. Madrid: Gredos, 1990.

CARVALHINHOS, Patrícia de Jesus; ANTUNES, Alessandra Martins. Princípios teóricos de Onomástica. Toponímia e Antroponímia: a questão do nome próprio. In: Círculo Fluminense de Estudos Filológicos e Lingüísticos, XI, 2007, Rio de Janeiro, Cadernos... Rio de Janeiro, 2007.

CURVELO, Heloísa Reis. Topônimos Maranhenses: testemunhos de um passado ainda presente. 2009. 347f. Dissertação (Mestrado em Linguística) - Universidade Federal do Ceará, Ceará, 2009.

DICK, Maria Vicentina de Paula do Amaral. Atlas Toponímico do Brasil: teoria e prática II. In: Revista Trama, v. 03, n. 05, p. 141-155, 2007a.

- A terminologia nas ciências onomásticas. Estudo de caso: o Projeto ATESP (Atlas Toponímico do Estado de São Paulo). In: ISQUERDO, Aparecida Negri (org.). As ciências do léxico: lexicologia, lexicografia, terminologia. v. III. Campo Grande: Editora. UFMS, 2007b.

. Fundamentos teóricos da Toponímia. Estudo de caso: o Projeto ATEMIGAtlas Toponímico de Estado de Minas Gerais (variante regional do Atlas Toponímico do Brasil). In: SEABRA, Maria Cândida Trindade Costa de (org.). O léxico em Estudo. Belo Horizonte: Faculdade de Letras da UFMG, 2006.

. Aspectos de Etnolinguística - a Toponímia Carioca e Paulistana - contrastes e confrontos. Seção Textos - Toponímia, n. 56, p. 180-91, dez./2002-fev./2003. Disponível em: <http://www.filologia.org.br/anais>. Acesso em: 14 out. 08. 
A motivação toponímica e a realidade brasileira. São Paulo: Edições do Arquivo do Estado, 1990a.

. Os vocabulários toponímicos básicos no "vocabulário na língua brasílica" e sua relação geográfica. Revista do Instituto de Estudos Brasileiros - IEB da Universidade de São Paulo, São Paulo, n. 31, p. 95-111, 1990 b.

. Toponímia e imigração no Brasil. Revista do Instituto de Estudos Brasileiros - IEB da Universidade de São Paulo, São Paulo, n. 29, p. 83-92, 1988.

. Toponímia e cultura. Revista do Instituto de Estudos Brasileiros - IEB da Universidade de São Paulo, São Paulo, n. 27 p. 93-101, 1987.

. O léxico toponímico: marcadores e recorrências lingüísticas (um estudo de caso: a toponímia do Maranhão). In: Revista Brasileira de Lingüística. São Paulo: Plêiade, v. 08, n. 01, p. 59-67, 1995.

LETELIER, Valentin. Ensayo de Onomatología ó estudio de los nombres propios y hereditários. Madrid: Libreria de Victoriano Suárez, s/d.

LEWANDOWSKY, Theodo Reis Diccionario de linguística. 5. ed. Madrid: Cátedra, 2000.

MENENDEZ PILDAL, Ramon. Toponimia prerromanica hispana. Madrid: Gredos, 1952.

NIETO BALLETER, Emilio. Breve diccionário de topónimos españoles. (s/l): Alianza Editorial, 1997.

PREFEITURA DE SÃO LUÍS. Instituto da Cidade, Pesquisa e Planejamento Urbano e Rural - INCID. Mapa Temático dos Bairros e Arruamento de São Luís, escala numérica aproximada de 1: 40. 000. São Luís: INCID, 2012.

SCHNEIDER, Marlene. A toponímia como representação da realidade regional. In: CONGRESSO INTERNACIONAL DA ASSOCIAÇÃO BRASILEIRA DE LINGÜÍSTICA - ABRALIN, 02, 2001, Fortaleza. Anais... Fortaleza: Imprensa Universitária/UFC, 2001.

VASCONCELOS, José leite de. Opúsculos, v. III, Coimbra: Imprensa da Universidade, 1931.

Recebido: 06/01/2018

Aceito: 10/06/2018 